BMJ Open Sport \& Exercise Medicine

\title{
Incidence and prevalence of lumbar stress fracture in English County Cricket fast bowlers, association with bowling workload and seasonal variation
}

\author{
Peter Alway, ${ }^{\oplus 1}$ Katherine Brooke-Wavell, ${ }^{1}$ Ben Langley, ${ }^{2}$ Mark King, ${ }^{1}$ \\ Nicholas Peirce ${ }^{2}$
}

To cite: Alway $P$,

Brooke-Wavell K, Langley B, et al. Incidence and prevalence of lumbar stress fracture in English County Cricket fast bowlers, association with bowling workload and seasonal variation. BMJ Open Sport \& Exercise Medicine 2019;5:e000529. doi:10.1136/ bmjsem-2019-000529

Accepted 9 April 2019
Check for updates

(C) Author(s) (or their employer(s)) 2019. Re-use permitted under CC BY-NC. No commercial re-use. See rights and permissions. Published by BMJ.

${ }^{1}$ SSEHS, Loughborough University, Loughborough, UK ${ }^{2}$ Science and Medicine, England and Wales Cricket Board, Loughborough, UK

Correspondence to Peter Alway;

P.Alway@lboro.ac.uk

\section{ABSTRACT}

Objectives Since much of the previous epidemiological research into lumbar stress fracture was conducted, there has been a marked increase in the amount of cricket being played. The aims were to determine the incidence and prevalence of lumbar stress fracture in English County Cricket fast bowlers between 2010 and 2016, determine the association with match bowling workload and observe seasonal variation in workload and injury.

Methods Lumbar stress fracture incidence and prevalence rates were calculated using new international methods for epidemiology in 368 professional English fast bowlers from 2010 to 2016 . Workload variables were compared between lumbar stress fracture case and noninjured control groups, before entry in a logistic regression. Results Fifty-seven lumbar stress fractures (mean age 22.81) were reported. Injury was most common in July and September. Match incidence was 0.16 lumbar stress fractures per 10000 deliveries, annual incidence was 2.46 lumbar stress fractures per 100 fast bowlers and annual prevalence of lumbar stress fractures was $1.67 \%$ of squad days. Significant workload variables were observed between cases and controls. A peak 7-day workload of greater than 234 deliveries significantly increased the odds of sustaining a lumbar stress fracture 11-fold compared with bowling fewer than 197 deliveries.

Conclusion Lumbar stress fractures are common in young fast bowlers possibly due to immaturity of the lumbar spine. The condensed early and late-season schedule may be causing periods of overuse, resulting in an increase in incidence of lumbar stress fracture. Reduction of workload in young fast bowlers is needed to reduce incidence.

\section{INTRODUCTION}

Fast bowling in cricket is a unique and forceful movement pattern defined by extreme trunk movements, ${ }^{1}$ great vertical ground reaction forces ${ }^{2}$ and high workloads. Compared with other playing roles, fast bowlers are considerably more active, ${ }^{3}$ and have greater prevalence of injury than any other playing role. ${ }^{4-7}$

\section{What are the new findings}

English professional cricket fast bowlers had a lumbar stress fracture match incidence of 0.13 per 10 000 balls, an annual incidence of 2.46 per 100 fast bowlers and a prevalence of $1.67 \%$ of total squad days between 2010 and 2016 .

- Risk of lumbar stress fracture is greatest in those aged 18-22, with an annual incidence of 4.90 stress fractures per 100 fast bowlers.

- Incidence of lumbar stress fracture was most common in July and September, possibly caused by the condensed multiday schedule at the beginning and end of the season.

- Bowling more than 234 deliveries in a 7-day period is a significant risk factor to lumbar stress fracture compared with bowling less than 197 deliveries (OR 11.00 , relative risk $3.18, p<0.01$ )

\section{Impact on clinical practice in the future}

Fast bowling workload guidelines should be implemented in professional cricket to reduce the incidence of lumbar stress fracture in fast bowlers under 25.

Although only composing between $3 \%$ and $12 \%$ of all injuries in cricket, ${ }^{4-9}$ lumbar stress fracture (LSF) result in the greatest time loss of any injury suffered in cricket. ${ }^{46710} \mathrm{LSF}$ is a fatigue injury, caused by the accumulation and propagation of microdamage across the neural arch of the lumbar vertebra, at a rate greater than the repair processes of bone. ${ }^{1112}$

To date, only studies in Australasia have analysed LSF from multiple years, used medical records as their injury source and have used cohorts of greater than 100 cricketers. $^{4-7} 13$ These have demonstrated that annual incidence of LSF has been 0.8-5.6 per 100 cricketers per season, with an annual 
prevalence of $0.1 \%-2.8 \%$ of matchdays missed per season. ${ }^{4-6}$ Many of these papers have been based on small populations of fast bowlers, often including the same players, and heavily relying on a single research group.

Since the majority of this research was conducted, the landscape of cricket has drastically altered. Twenty over cricket (T20) has led to the establishment of multimonth blocks of near exclusively T20 fixtures, as well as the proliferation of T20 tournaments leading to a substantial $(10 \%-30 \%)$ increase in matchdays. ${ }^{14}$ This increase in matchdays may explain the higher risk of sustaining an injury compared with the pre-T20 era, ${ }^{15}$ possibly due to the increased intensity of T20. ${ }^{314}$

The increase in matchdays and year-round nature of T20 has resulted in the production of a new international injury definition consensus. ${ }^{16}$ To date, the only research which used the recommendations demonstrated an annual incidence of 3.2 LSF per 100 Australian cricketers. ${ }^{6}$ It is not known if these results are mirrored in English cricketers, as the environmental factors, field sizes, pitch conditions and match schedules differ between countries.

One of the risk factors to injury in fast bowlers is match workload, ${ }^{47-21}$ but few studies have investigated the link to LSF. It has been suggested that bowlers with a high 90-day workload coupled with low-career workload have a significantly greater risk of suffering LSF. ${ }^{17}$ It is important to elucidate the relationship of workload to injury risk, to allow workload guidelines to reduce injury risk.

The aim of this paper is to determine contemporary LSF epidemiology and relationship with workload in professional cricket fast bowlers. Specific objectives are to determine the incidence and prevalence of LSF in English professional fast bowlers across a 7-year period using the recent international cricket consensus definition, ${ }^{16}$ to quantify seasonal variation in incidence of LSF and workload and to assess the relationship between workload and LSF.

\section{METHODOLOGY}

\section{Data collection}

Prospective surveillance of injury was used to determine injury incidence and prevalence, while a nested casecontrol study was used to examine associations of injury with workload. Participants were fast bowlers who bowled greater than $10 \%$ of the deliveries in one of the multiday or limited overs first or second XI English County teams for at least 1 year between 2010 and 2016 .

Injury data were extracted from an England and Wales Cricket Board injury database, in which all time loss injuries are required to be registered and updated by medical professionals working within each county team. Incidence and prevalence of LSF conformed to the recent international cricket injury consensus definitions. ${ }^{16} \mathrm{LSF}$ definition required the diagnosis to be made based on symptomatic presentation and radiological evidence (MRI, CT or single-photon emission CT), which resulted in a player being unavailable for match selection, irrespective of whether a match was scheduled. Recovery was determined as when a physiotherapist determined the player had returned to match availability, irrespective of whether a match was scheduled.

Workload variables were extracted from publicly available club, county and international scorecards across all formats of cricket. ${ }^{22}$ For the purposes of this study, the English season was defined as the period from 1 March to 28 February.

\section{Analysis}

All data were collated in a spreadsheet (Microsoft Excel, USA) and all analyses were undertaken using SPSS (V.23, IBM). Primary outcomes included the injury diagnoses, time loss, incidence and prevalence. Match incidence was defined as the number of LSFs per 10000 deliveries. Annual injury incidence was defined as number of LSFs per 100 fast bowlers. Annual injury prevalence was defined as the percentage of squad days a fast bowler was unavailable for due to LSF. Means, SDs and 95\% CIs were calculated.

Secondary outcomes included the age at injury, time of injury (early season: April and May; mid-season: June and July; late season: August and September; winter: October to March), injury location and workload variables, including mean 7, 28, 90 and 365-day workloads immediately preceding the injury, and peak 7, 28 and 90-day workloads within the season of injury.

Workloads of LSF cases were compared with non-injured controls using bivariate analysis. Analyses were repeated for early-season, mid-season and late-season injuries. If normally distributed, an independent samples t-test was used, otherwise a Mann-Whitney U test was used, with effect sizes calculated. ${ }^{23}$ Peak workload variables which significantly differed between cases and controls were categorised into workload groups by assessing quartiles of the controls. To further explore associations of LSF with workload, a singular multivariate analysis was conducted using binary logistic regression, using peak workloads within the same season as LSF. A backward stepwise method was used, which removed variables which did not have a significant $(p>0.05)$ effect on the model and reduces the risk of type II error and ORs of quartiles were compared with the low quartile as reference. Workloads 'at injury' were excluded from the multivariate analysis as LSFs are a gradual-onset injury, ${ }^{12}$ which is likely to affect workload.

\section{RESULTS}

A total of 368 participants were identified as fast bowlers between 2010 and 2016 (24.87 \pm 6.01 years), $46(12.5 \%)$ of whom suffered 57 LSFs across 2316 player-years. Match incidence was $0.13 \mathrm{LSF}$ per 10000 deliveries, annual incidence was 2.46 LSF per 100 fast bowlers, while prevalence of LSF resulted in $1.67 \%$ of squad days being missed at any one time with a mean time loss of $239 \pm 120$ days per injury. Most LSFs (74\%) were in bowlers aged under 25 years, with $56 \%$ occurring between ages 18 and 22 . 


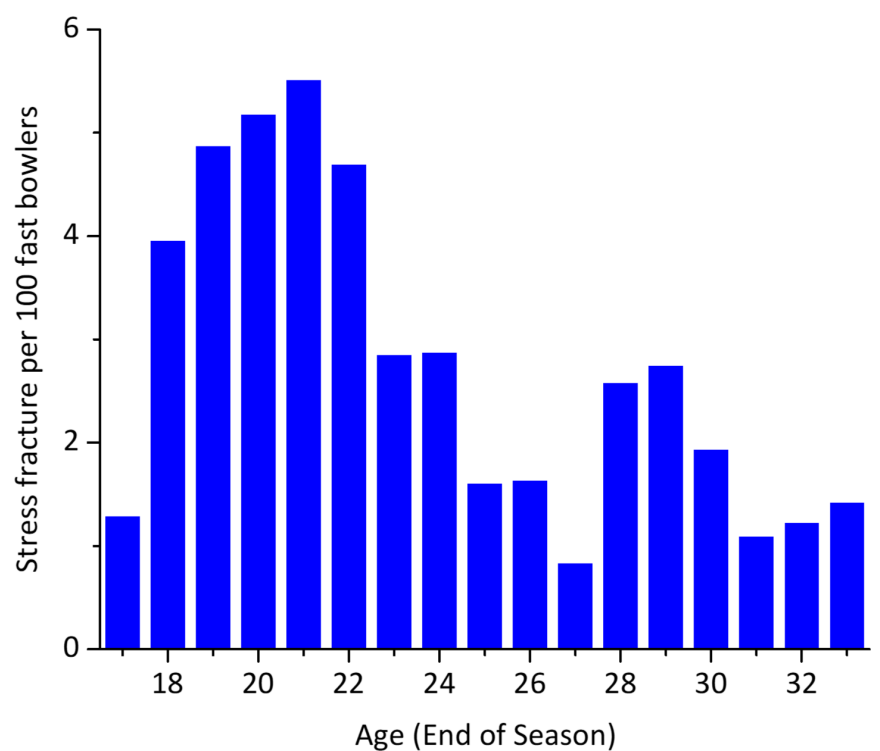

Figure 1 Annual incidence of lumbar stress fracture per age.

Match incidence in 18-22 year-olds was 0.32 per 10000 deliveries, annual incidence was 4.90 per 100 fast bowlers (figure 1) and prevalence was $3.21 \%$ of squad days. There was a trend to greater incidence and prevalence of LSF in 2016, compared with the 2010-2016 mean (table 1). The most common month for LSF was September, followed by July (figure 2A,B).

LSFs were most common at L4 and L5 vertebrae (35\%-32\% respectively) with $93 \%$ of LSF occurring contralateral to the bowling arm, at the pedicle $(22.8 \%)$ or pars interarticularis $(77.2 \%)$. Similar time loss was observed between L4 and L5, while LSF at L3 had the greatest time loss (table 2).

At any time, 7, 28 and 90-day workloads of cases were significantly greater than controls at injury $(36 \%, 26 \%$ and $30 \%$, respectively) and at peak value $(22 \%, 20 \%$ and $29 \%$, respectively). Early-season cases demonstrated significantly greater 7, 28 and 90-day peak workloads than controls (38\%, $42 \%$ and $106 \%$, respectively). No significant differences in workload variables were observed between mid-season cases and controls. Late-season cases displayed significantly greater 90 and 365-day workloads at injury (39\% and 28\%, respectively), and 7, 28 and 90-day peak workloads $(23 \%, 25 \%$ and $30 \%$, respectively: table 3).

Late-season cases had significantly greater 90 -day workloads from 81 days prior to injury compared with controls (figure 3D), with a significant difference in 28-day workload between 80 and 28 days before injury (figure 3C).
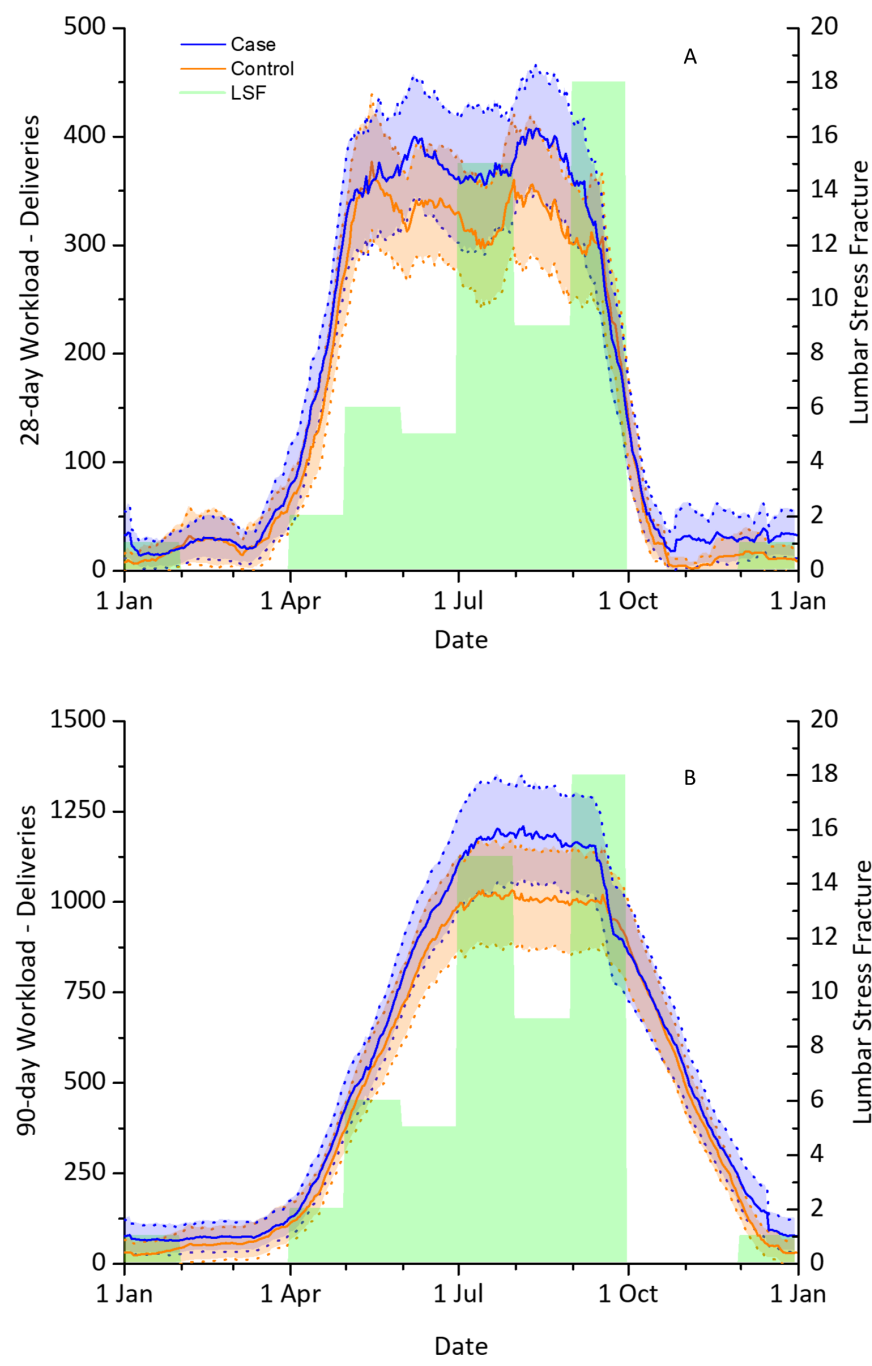

Figure 2 Seasonal variation of lumbar stress fracture and workload. Mean and $95 \% \mathrm{Cl}$ of the 365 days prior to lumbar stress fracture (LSF) in both 28-day (A) and 90-day (B) variables in all lumbar stress fracture cases $(n=57)$ and controls $(n=57)$.

No significant differences were observed in 28 or 90-day workloads between mid-season LSF cases and controls (figure 3A,B).

Analysis of quartiles created workload groups for use in a binary logistic regression (7-day peak: $\leq 197,198-233$, 234-293 and $\geq 294$; 28-day peak: $\leq 400,401-536,537-711$ and $\geq 712$; 90-day peak: $\leq 642,643-1081,1082-1483$ and $\geq 1484$ ). Binary logistic regression demonstrated that 7-day workloads significantly contribute to stress fracture $(\mathrm{p}=0.007)$, while 28 and 90-day workloads did not ( $>0.05)$. Peak 7-day workloads of between 234-293

Table 1 Match incidence, annual incidence and annual prevalence of lumbar stress fracture

\begin{tabular}{lllllllll}
\hline & $\mathbf{2 0 1 0}$ & $\mathbf{2 0 1 1}$ & $\mathbf{2 0 1 2}$ & $\mathbf{2 0 1 3}$ & $\mathbf{2 0 1 4}$ & $\mathbf{2 0 1 5}$ & $\mathbf{2 0 1 6}$ & All (95\% Cl) \\
\hline Match incidence (per 10 000 deliveries) & 0.14 & 0.06 & 0.09 & 0.18 & 0.1 & 0.15 & 0.23 & 0.13 (0.10 to 0.17) \\
Annual incidence (per 100 fast bowlers) & 2.61 & 1.14 & 1.45 & 3.55 & 1.79 & 2.89 & 4.12 & $2.46(1.82$ to 3.10$)$ \\
Annual prevalence (\% squad days unavailable) & 1.56 & 0.96 & 0.83 & 1.62 & 1.29 & 2.15 & 3.63 & 1.67 (1.64 to 1.70$)$ \\
\hline
\end{tabular}


Table 2 Location, age and time loss of lumbar stress fracture

\begin{tabular}{lllll}
\hline Location & Incidence & Non-dominant (\%) & Mean age: years (mean \pm SD) & Time loss: days (mean, 95\% Cl) \\
\hline L3 & 7 & 100 & $21.57 \pm 2.35$ & 304 (160 to 448) \\
L4 & 20 & 90 & $22.52 \pm 3.61$ & $211(163$ to 237) \\
L5 & 18 & 89 & $23.37 \pm 4.36$ & $233(190$ to 298) \\
Bilateral & 3 & N/A & $24.61 \pm 8.13$ & $247(0$ to 752$)$ \\
Multiple & 6 & 100 & $22.30 \pm 4.21$ & $263(86$ to 440$)$ \\
Unknown & 3 & N/A & $23.57 \pm 3.40$ & $261(61$ to 461$)$ \\
Total & 57 & 93. & $22.81 \pm 3.96$ & $239(207$ to 271) \\
\hline
\end{tabular}

N/A, not applicable.

deliveries and in excess of 294 deliveries significantly increased the odds and risk of sustaining LSF compared with bowling fewer than 197 deliveries (234-293: OR $11.00,95 \%$ CI 2.16 to 55.92 , relative risk (RR) $3.18,95 \%$ CI 1.68 to 3.86 ; $\geq 294$ : OR $11.67,95 \%$ CI 2.32 to 58.60 , RR $3.06,95 \%$ CI 1.72 to 3.63 , figure 4 ). This model correctly classified $66 \%$ of fast bowlers as injured or uninjured with $82 \%$ sensitivity and $49 \%$ specificity.

\section{DISCUSSION}

This study was the largest epidemiological study of LSF in cricket, and the first in the Northern Hemisphere in over a decade. It contained the largest number of LSFs recorded in cricket and was the first to determine seasonal variations in both LSF incidence and workload in fast bowlers and to include the impact of T20 competitions in the England and Wales professional game. Additionally, it was the first to measure both incidence and prevalence of LSF using the updated international cricket injury consensus. ${ }^{16}$ This study has demonstrated that LSFs occur more commonly at the $\mathrm{L} 4$ and $\mathrm{L} 5$ vertebrae, with the majority in fast bowlers aged under 25, with exceeding 234 deliveries in a 7-day period significantly increasing the odds of LSF 11-fold compared with bowling less than 197 deliveries

\section{Epidemiology}

To date, the only paper which adhered to the new injury consensus demonstrated that annual incidence of LSF in Australian cricket was 3.2 per 100 cricketers, ${ }^{6}$ greater than the 2.46 per 100 fast bowlers found in this study. Incidence of LSF may be fewer in the current study due to numerous factors, all of whom require further study to definitively determine differences between countries. The size of the oval is generally larger in Australia, increasing workload volume. The pitches in Australia are harder than in England, potentially resulting in greater attenuation of vertical ground reaction forces, ${ }^{24}$ and produce longer innings, resulting in increased workload. It is likely there are differences in strength and conditioning, fixture scheduling, childhood activities and ethnicity between countries, which may have an additional effect on the incidence of LSF.

The higher incidence and prevalence of LSF identified in 2016 both in this study and in Australia ${ }^{6}$ is potentially concerning due to the long time loss associated with this injury. This may in part be associated with increased imaging, detection and routine screening but may also be the result of the increase in the amount of cricket being played across the world. ${ }^{14}$

Compared with other research, time loss per LSF was much greater in this study, increasing from 169 days per $\mathrm{LSF}^{10}$ to 237 days. It is possible that LSF cases were of a more serious nature than those in previous studies, or that the English medical attitude towards management and rehabilitation of LSF has become more conservative. Interestingly, a nearly equal number of LSFs are observed at L4 and L5, with smaller incidence at L3, while in other sports, most LSFs $(84 \%)$ are at L5. ${ }^{25}$ This may suggest that LSFs in fast bowlers, particularly injuries suffered at L4, have an aetiology different from those in other sports.

Young fast bowlers were most susceptible to suffering LSF, consistent with previous research in fast bowlers ${ }^{17} 2627$ as well as across other activities which involve repetitive loading of the lumbar spine including gymnastics, rowing and javelin. ${ }^{25}$ This is possibly due to the failure to achieve the necessary bone resilience ${ }^{28}$ to withstand repetition of substantial loading of fast bowling, which generates large ground reaction forces ${ }^{2}$ combined with extreme multiplanar trunk movements, ${ }^{1}$ which places large torsional, shear and compressive stress on the lumbar spine. ${ }^{29-31}$ Young fast bowlers may also be susceptible to LSF due to the later maturation of the lumbar spine compared with other skeletal sites: full ossification of the lumbar spine may not be attained until 25 years. ${ }^{32}$ It may be that bowling guidelines are needed for bowlers beyond 19 years until complete maturation of the spine has been achieved.

\section{Workload}

A peak 7-day workload of greater than 234 deliveries was a significant risk factor to LSF. This mirrors previous research which found high incidence of LSF after bowling greater than 240 deliveries in a 7-day period. ${ }^{33}$ However, the current study differs from a previous logistic regression which found that a high (>900 deliveries) 90-day workload significantly contributed to LSF. ${ }^{17}$

The large forces involved in fast bowling may generate high strain rates in the neural arch that may be close to, or exceed, the threshold for microdamage, particularly in young bowlers and/or those who are less well 
Table 3 Mean \pm SD or median (IQR) differences in workload between cases and controls

\begin{tabular}{|c|c|c|c|c|c|}
\hline Time of year & Workload & Cases & Controls & $P$ value & Effect Size \\
\hline All & & $\mathrm{n}=57$ & $n=57$ & & \\
\hline \multirow[t]{6}{*}{ Workload at injury } & Age & $22.81 \pm 2.96$ & $22.97 \pm 4.20$ & & \\
\hline & Career & $12741 \pm 9648$ & $12406 \pm 9305$ & 0.893 & 0.03 \\
\hline & 7 days $^{*}$ & $126(66,192)$ & $90(36,156)$ & 0.020 & 0.31 \\
\hline & 28 days* & $428(313,521)$ & $336(228,480)$ & 0.017 & 0.31 \\
\hline & 90 days* & $1135(863,1481)$ & $876(553,1332)$ & 0.005 & 0.37 \\
\hline & 365 days & $2413 \pm 807$ & $2130 \pm 883$ & 0.076 & 0.34 \\
\hline \multirow[t]{3}{*}{ Peak workload } & 7 days & $289 \pm 61$ & $238 \pm 72$ & $<0.001$ & 0.77 \\
\hline & 28 days & $664 \pm 173$ & $554 \pm 112$ & 0.003 & 0.57 \\
\hline & 90 days & $1410 \pm 516$ & $1097 \pm 533$ & 0.002 & 0.60 \\
\hline Early-season injury & & $\mathrm{n}=8$ & $\mathrm{n}=8$ & & \\
\hline \multirow[t]{6}{*}{ Workload at injury } & Age & $23.32 \pm 4.08$ & $23.45 \pm 3.89$ & & \\
\hline & Career & $13078 \pm 7264$ & $13206 \pm 7596$ & 0.973 & 0.02 \\
\hline & 7 days & $161 \pm 60$ & $108 \pm 68$ & 0.123 & 0.83 \\
\hline & 28 days & $473 \pm 77$ & $357 \pm 182$ & 0.117 & 0.82 \\
\hline & 90 days & $721 \pm 206$ & $492 \pm 271$ & 0.078 & 0.95 \\
\hline & 365 days ${ }^{*}$ & $2075(2277,2384)$ & $1983(1682,2794)$ & 0.959 & 0.04 \\
\hline \multirow[t]{3}{*}{ Peak workload } & 7 days & $261 \pm 33$ & $189 \pm 65$ & 0.014 & 1.40 \\
\hline & 28 days & $562 \pm 71$ & $393 \pm 195$ & 0.038 & 1.15 \\
\hline & 90 days & $1013 \pm 409$ & $492 \pm 271$ & 0.010 & 1.50 \\
\hline Mid-season injury & & $n=20$ & $n=20$ & & \\
\hline \multirow[t]{6}{*}{ Workload at injury } & Age & $23.18 \pm 4.31$ & $23.55 \pm 4.98$ & & \\
\hline & Career & $14472 \pm 11437$ & $13810 \pm 11255$ & 0.777 & 0.06 \\
\hline & 7 days & $110 \pm 60$ & $114 \pm 84$ & 0.861 & 0.05 \\
\hline & 28 days & $409 \pm 185$ & $388 \pm 161$ & 0.702 & 0.12 \\
\hline & 90 days & $1175 \pm 439$ & $1093 \pm 505$ & 0.588 & 0.17 \\
\hline & 365 days & $2390 \pm 822$ & $2289 \pm 813$ & 0.699 & 0.12 \\
\hline \multirow[t]{3}{*}{ Peak workload } & 7 days & $283 \pm 73$ & $245 \pm 60$ & 0.083 & 0.57 \\
\hline & 28 days & $644 \pm 173$ & $605 \pm 179$ & 0.489 & 0.22 \\
\hline & 90 days & $1355 \pm 451$ & $1217 \pm 472$ & 0.350 & 0.30 \\
\hline Late-season injury & & $\mathrm{n}=27$ & $\mathrm{n}=27$ & & \\
\hline \multirow[t]{6}{*}{ Workload at injury } & Age & $22.29 \pm 3.78$ & $22.33 \pm 3.69$ & & \\
\hline & Career & $11387 \pm 8812$ & $11014 \pm 8081$ & 0.986 & 0.04 \\
\hline & 7 days* & $120(57,197)$ & $78(39,139)$ & 0.061 & 0.36 \\
\hline & 28 days* & $408(285,523)$ & $263(162,485)$ & 0.071 & 0.35 \\
\hline & 90 days $^{*}$ & $1238(1097,1686)$ & $1032(559,1335)$ & 0.008 & 0.51 \\
\hline & 365 days & $2523 \pm 821$ & $1974 \pm 885$ & 0.022 & 0.64 \\
\hline \multirow[t]{3}{*}{ Peak workload } & 7 days & $305 \pm 57$ & $247 \pm 79$ & 0.040 & 0.84 \\
\hline & 28 days & $710 \pm 185$ & $567 \pm 224$ & 0.013 & 0.70 \\
\hline & 90 days & $1559 \pm 541$ & $1199 \pm 528$ & 0.017 & 0.67 \\
\hline
\end{tabular}

Parametric ( $d=$ ) effect size: small $\geq 0.20$; moderate $\geq 0.50$; large $\geq 0.80$. Non-parametric $(r=)$ effect size: small $\geq 0.10$; moderate $\geq 0.30$; large $\geq 0.50$.

*Denotes non-parametric.

adapted. ${ }^{34-37}$ Once the microdamage threshold range is exceeded, microdamage may occur. With a high workload, microdamage may accumulate and propagate stimulating bone resorption that may increase crack propagation with continued loading, resulting in stress fracture. ${ }^{1137}$ As LSF is a gradual-onset injury, ${ }^{12}$ it is unlikely that symptoms will manifest immediately, so fast bowlers continue to bowl in a state of pathological overload, reflected in cases at the end of the season (figure 3D), where their 90-day workload was significantly greater than controls for the 81 days leading up to LSF. This is further corroborated as cases bowled significantly greater peak 7, 28 and 90 days than controls, and bowled significantly greater 7, 28 and 90-day workloads immediately prior to injury. It could be suggested 

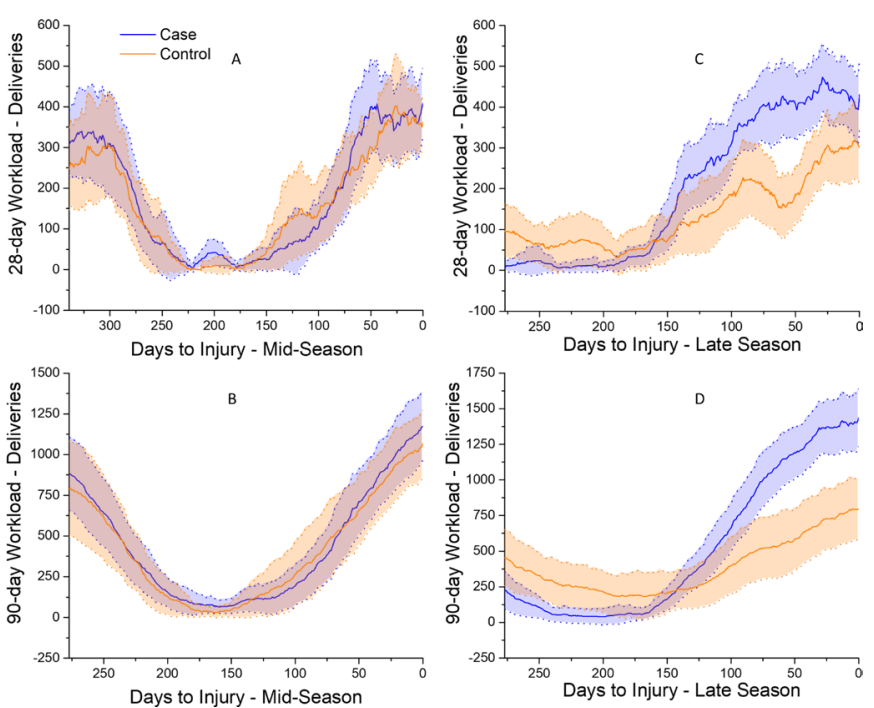

Figure 3 Mean and $95 \% \mathrm{Cl}$ of workload patterns before lumbar stress fracture in cases (blue) and controls (orange). Comparison of mid-season 28-day (A) and 90-day (B) workloads between cases $(n=20)$ and controls $(n=20)$. Comparison of late-season 28-day (C) and 90-day (D) workloads between cases $(n=27)$ and controls $(n=27)$.

that a 7-day peak workload of greater than 234 deliveries is the trigger to LSF, with sustained overuse exploiting the damage to the bone caused by a great peak 7-day workload.

The popularity of T20 has led to the establishment of a block of T20 in the middle of the English season, which can be observed by the reduction of 28-day workload in mid-season (figure 2A). This may contribute to the spike in LSF in both July and September (figure 2A,B), as the multiday competition is condensed into early and late seasons, and LSFs are known to occur 3-4 weeks following high workloads. ${ }^{33}$ Cases in both early and late seasons had significantly greater peak workloads than controls (table 1), suggesting that this is a period of overuse with inadequate recovery. Further, at the end of the season, cases sustained a significantly greater 28 and 90-day workload for 28-80 and 81-0 days prior to LSF, respectively (figure 3C,D). This may suggest that many fast bowlers are not getting the rest which they require to allow microdamage to heal.

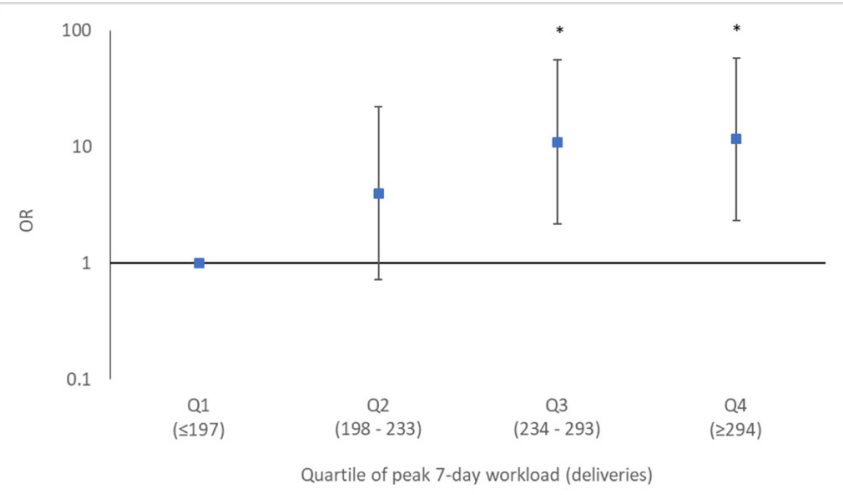

Figure 4 OR and $95 \% \mathrm{Cl}$ of peak 7-day workload quartiles. ${ }^{*}$ Denotes significantly different from quartile $1(p<0.01)$.
Alternatively, the sustained reduction in workload during the T20 block may result in disuse mode remodelling of bone, ${ }^{35}$ reducing the resilience of the lumbar spine to fast bowling, increasing the risk of LSF during late-season multiday fixtures. A change in fixture scheduling may be required, with multiday cricket played throughout the year, or the restriction of number of overs for younger bowlers. This would require reserve bowlers that alternate within a game unless the rules of cricket are changed to allow a more radical use of second inning fast bowling substitutes.

No significant differences in workload variables were observed between mid-season cases and controls (table 1, figure 3A,B). Mid-season LSF may be more dependent on risk factors other than workload, including intensity, bowling technique, ${ }^{1}$ musculoskeletal factors, ${ }^{30}$ previous injury $^{38}$ or hereditary factors. ${ }^{39}$ It is possible that the increased use of variations, such as slower balls, by fast bowlers during T20 may result in changes in bowling technique which may load different, potentially less adapted, areas of the lumbar spine; however, this requires further research.

The strengths of this study include the large fast bowling cohort, prospective injury surveillance and the large number of stress fracture cases. The limitations of this research are that information was only available for senior competition: training workload and some youth cricket were not included. While playing overseas or for amateur teams, there may have been less access to medical support, which may result in an under-reporting of LSF.

\section{Future research}

There is a need for LSF epidemiology to be reported from medical records in other countries. Future research studying relationships between workload and LSF should include training workload, as well as regular MRI screening, as many LSFs are asymptomatic. ${ }^{40}$ Further investigations between age, workload and LSF are needed given the greater incidence of LSF in younger fast bowlers and there may well be lessons to be learnt in relation to protective workload planning, especially from further analysis of these data sets and looking at bowlers who did not sustain stress fractures. Furthermore, comparisons with other unilateral throwing sports, such as baseball, where pitchers up to age 22 are subject to pitch limits and rest periods to prevent arm injuries, ${ }^{41}$ may well be highly informative. Finally, LSFs which occur in mid-season which are not attributed to excessive workload need to be investigated to determine aetiology.

\section{CONCLUSION}

This study has demonstrated that bowling greater than 234 deliveries in a week and/or being in a period of bowling overuse is a considerable risk factor in the development of LSF in young cricket fast bowlers. Given the immaturity of the lumbar spine in young fast bowlers, the authors recommend that bowling workload guidelines be instigated for fast bowlers up to the age of 25 years. This study demonstrated seasonal variation in stress fracture incidence and 
workload. A spike in incidence at the beginning and end of the season appears to be related to an increase in multiday cricket at this time, a possible side effect of the mid-season T20 block. A change in scheduling, restriction of bowling load for developing fast bowlers between 19 and 24 years, and therefore larger bowling squads, or potentially the use of second inning fast bowling substitutes all should be discussed to reduce incidence of LSF. Finally, our study demonstrated that workload significantly differs between cases and controls in early and late seasons, but not in mid-season, suggesting workload in early and late seasons should be particularly carefully reviewed.

Acknowledgements David Newman is acknowledged for extracting injury data from the ECB database.

Contributors PA, NP and KBW undertook the planning for the project, with advice from BL and MK. Data were collected and entered by PA. Data were analysed by $\mathrm{PA}, \mathrm{NP}$ and KBW. MK and BL assisted with interpretation of results. Responsibility for the content of the paper lies with PA, KBW and NP.

Funding The authors have not declared a specific grant for this research from any funding agency in the public, commercial or not-for-profit sectors.

\section{Competing interests None declared.}

Patient consent for publication Not required.

Ethics approval Ethical approval was obtained from Loughborough University Ethics Committee (Human Participants Sub-Committee, proposal number G18-P6).

Provenance and peer review Not commissioned; externally peer reviewed. Data availability statement No data are available.

Open access This is an open access article distributed in accordance with the Creative Commons Attribution Non Commercial (CC BY-NC 4.0) license, which permits others to distribute, remix, adapt, build upon this work non-commercially, and license their derivative works on different terms, provided the original work is properly cited, appropriate credit is given, any changes made indicated, and the use is non-commercial. See: http://creativecommons.org/licenses/by-nc/4.0/.

\section{REFERENCES}

1. Ranson CA, Burnett AF, King M, et al. The relationship between bowling action classification and three-dimensional lower trunk motion in fast bowlers in cricket. J Sports Sci 2008;26:267-76.

2. Worthington $P$, King M, Ranson $C$. The influence of cricket fast bowlers' front leg technique on peak ground reaction forces. $J$ Sports Sci 2013;31:434-41.

3. Petersen CJ, Pyne D, Dawson B, et al. Movement patterns in cricket vary by both position and game format. J Sports Sci 2010;28:45-52.

4. Orchard Jet al. Injuries in Australian cricket at first class level $1995 / 1996$ to $2000 / 2001{ }^{*}$ commentary. Br J Sports Med 2002;36:270-4. discussion 275.

5. Orchard JW, James T, Portus MR. Injuries to elite male cricketers in Australia over a 10-year period. J Sci Med Sport 2006;9:459-67.

6. Kountouris A, Sims K. Incidence and prevalence of elite male cricket injuries using updated consensus definitions. Open access $J$ Sport Med 2016;7:187-94.

7. Frost WL, Chalmers DJ. Injury in elite New Zealand cricketers 20022008: descriptive epidemiology. Br J Sports Med 2014;48:1002-7.

8. Foster D, John D, Elliott B, et al. Back injuries to fast bowlers in cricket: a prospective study. Br J Sports Med 1989;23:150-4.

9. Mansingh A, Harper L, Headley $S$, et al. Injuries in West Indies cricket 2003-2004. Br J Sports Med 2006;40:119-23.

10. Ranson CA, Burnett AF, Kerslake RW. Injuries to the lower back in elite fast bowlers: acute stress changes on MRI predict stress fracture. J Bone Joint Surg Br 2010;92:1664-8.

11. Miller TL, Best TM. Taking a holistic approach to managing difficult stress fractures. J Orthop Surg Res 2016;11.

12. Kountouris A, Saw R, Saw A. Management of lumbar Spondylolysis in athletes: role of imaging. Curr Radiol Rep 2018;6.

13. Orchard Jet al. Changes to injury profile (and recommended cricket injury definitions) based on the increased frequency of Twenty20 cricket matches. OAJSM 2010;1:63-76.
14. McNamara DJ, Gabbett TJ, Naughton G. Assessment of workload and its effects on performance and injury in elite cricket fast bowlers. Sport Med 2017:1-13.

15. Orchard JW, Blanch P, Paoloni J, et al. Fast bowling match workloads over $5-26$ days and risk of injury in the following month. $J$ Sci Med Sport 2015;18:26-30.

16. Orchard JW, Ranson C, Olivier B, et al. International consensus statement on injury surveillance in cricket: a 2016 update. $\mathrm{Br} \mathrm{J}$ Sports Med 2016;50:1245-51.

17. Orchard JW, Blanch P, Paoloni J, et al. Cricket fast bowling workload patterns as risk factors for tendon, muscle, bone and joint injuries. Br J Sports Med 2015;49:1064-8.

18. Dennis R, Farhart R, Goumas C, et al. Bowling workload and the risk of injury in elite cricket fast bowlers. J Sci Med Sport 2003;6:359-67.

19. Dennis RJ, Finch CF, Farhart PJ. Is bowling workload a risk factor for injury to Australian junior cricket fast bowlers? Br J Sports Med 2005;39:843-6.

20. Hulin BT, Gabbett TJ, Blanch P, et al. Spikes in acute workload are associated with increased injury risk in elite cricket fast bowlers. $\mathrm{Br} J$ Sports Med 2014;48:708-12.

21. Warren A, Williams S, McCaig S, et al. High acute:chronic workloads are associated with injury in England \& Wales Cricket Board Development Programme fast bowlers. J Sci Med Sport 2018;21:40-5.

22. Cricket Archive. Home. Available: http://www.cricketarchive.com/ [Accessed 1 Nov 2017].

23. Cohen J. Statistical power analysis for the Behvaioral sciences. 2nd edn. London: Routledge, 1988.

24. Biomechanics NBM. Load analysis and sports injuries in the lower extremities. Sport Med An Int J Appl Med Sci Sport Exerc 1985;2:367-79.

25. Soler T, Calderón C. The prevalence of spondylolysis in the Spanish elite athlete. Am J Sports Med 2000;28:57-62.

26. Stretch RA. Junior cricketers are not a smaller version of adult cricketers: a 5-year investigation of injuries in elite junior cricketers. S Afr J SM 2014;26:123-7.

27. Blanch P, Orchard J, Kountouris A, et al. Different tissue type categories of overuse injuries to cricket fast bowlers have different severity and incidence which varies with age. J Sci Med Sport 2014;18:e159-60.

28. Hind K, Bansil K, Barlow M, et al. Novel bilateral analysis of AP lumbar spine bone density in elite cricket fast bowlers. In: ISCD 22nd Annual Meeting. Dublin 2016.

29. Crewe $\mathrm{H}$, Campbell A, Elliott B, et al. Lumbo-pelvic loading during fast bowling in adolescent cricketers: the influence of bowling speed and technique. J Sports Sci 2013;31:1082-90.

30. Bayne H, Elliott B, Campbell A, et al. Lumbar load in adolescent fast bowlers: a prospective injury study. J Sci Med Sport 2016;19:117-22.

31. Chosa E, Totoribe K, Tajima N. A biomechanical study of lumbar spondylolysis based on a three-dimensional finite element method. $J$ Orthop Res 2004;22:158-63.

32. Bogduk N. Clinical anatomy of the lumbar spine and sacrum. 3rd edn. New York: Churchill Livingstone, 1997.

33. Orchard JW, James T, Portus M, et al. Fast bowlers in cricket demonstrate up to 3- to 4-week delay between high workloads and increased risk of injury. Am J Sports Med 2009;37:1186-92.

34. Frost HM. Bone ' mass ' and the 'Mechanostat ': a proposal. Anat Rec 1987;219:1-9.

35. Frost HM. Bone's mechanostat: a 2003 update. Anat Rec 2003;275A:1081-101.

36. Turner $\mathrm{CH}$. Three rules for bone adaptation to mechanical stimuli. Bone 1998;23:399-407.

37. Hughes JM, Petit MA. Biological underpinnings of frost's mechanostat thresholds: the important role of osteocytes. $J$ Musculoskelet Neuronal Interact 2010;10:128-35.

38. Davies R, Du Randt R, Venter D, et al. Cricket: nature and incidence of fast-bowling injuries at an elite, junior level and associated risk factors. S. Afr. j. sports med. 2009;20:115-8.

39. Ward CV, Latimer B, Alander DH, et al. Radiographic assessment of lumbar facet distance spacing and Spondylolysis. Spine 2007;32:E85-8.

40. Ranson CA, Kerslake RW, Burnett AF, et al. Magnetic resonance imaging of the lumbar spine in asymptomatic professional fast bowlers in cricket. J Bone Joint Surg Br 2005;87:1111-6.

41. Baseball PU. Guidelines for youth and adolescent pitchers. Available: http://m.mlb.com/pitchsmart/pitching-guidelines/ [Accessed 27 Oct 2018]. 